\title{
The Effect of a 12-Week Exercise Intervention on Falls in Primary Care ${ }^{1}$
}

\author{
Şirin TOPÇU YALÇIN ${ }^{2}$
}

\author{
Emrah ATAY ${ }^{3}$
}

Hakan YAMAN ${ }^{4}$

\footnotetext{
${ }^{2}$ Ministry of Education, Manavgat Rukiye Raşit Meşhur Vocational High school, ANTAL YA, Turkey

${ }^{3}$ Mehmet Akif Ersoy University, School of Physical Education, BURDUR, Turkey

${ }^{4}$ Akdeniz University, Faculty of Medicine, Department of Family Medicine, ANTALYA, Turkey
}

Tag: Topçu Yalçın, Ş. Atay, E. ve Yaman, H. (2018). The Effect of a 12-Week Exercise Intervention on Falls in Primary Care. Gaziantep University Journal of Sports Sciences, 3(2): 98-113.

\begin{abstract}
Community-based interventions show a decrease in morbidity according to falls and interventions covering exercise and home safety measures were superior to solve educational activities. The aim of this study is to evaluate the effect of a 12-week balance, strength and aerobic training on balance and conditional tests in people aged 55 years and over. The study was performed in a primary health care center in Antalya, South-Turkey. A sample of 199 patients have been invited. After randomization, the intervention group received instructions about the falls prevention and endurance, strength, balance and flexibility training. Patients were counseled once a week and supported monthly with a elastic band(according their level of strength). Two measurements with Fullerton Advanced Balance Scale (FAB), Balance Efficacy Scale (BES), Health and Activity Questionnaire (HAQ), of the Falls Prevention Program; and physical condition measurements have been performed. The number of participants both in the intervention and control groups were 73; however, 7 patients from the intervention group and 9 patients from the control group dropped out before the lass evaluation at the 12th week. The scores of FAB and BES, the Chair Stand Test Repetition Frequency, Chair Sit and Reach Test, Back Scratch Test, Arm Curl Test, Two Minutes Step Test, and the Fifty Feet Walk Test showed a significant difference at the end of the intervention and in the intervention group. Improvements in conditional factors (strength, flexibility and balance) were observed. A decrease in fall frequency was not observed. We recommend a promising intervention, which could be implemented in alow-resourced setting and which could reduce falls in long-term.
\end{abstract}

\section{Original Article}

Article Info

Received: 17.05 .2018

Accepted: 18.06.2018

Published: 20.06.2018

\section{Corresponding Author}

e-mail: sirintopcu@gmail.com

DOI: $10.31680 /$ gaunjss.424389

Key Words: Falls, Exercise, Prevention, Health Promotion, Plates Practice

\footnotetext{
${ }^{1}$ The data of this study has been partially retrieved from a Master of Science Dissertation by Şirin Topçu (2009).
} 


\section{Introduction}

People aged 65 years or older have a prevalence of $30-40 \%$ falls at least once a year (Freiberger et al.,2013; Gillespie et al.,2012). Once who have fallen are more prone to falls and the prevalence of these incidents increase to $40-50 \%$ in people over 79 (Gillespie et al.,2012; Tinetti et al.,1988). Falls can lead to morbidity and mortality of aging people (J Am Geriatr,2011) and several interventions have shown a decrease of fall rates by $20-40 \%$ (Gillespie et al.,2012).

Falls are accepted as a geriatric syndrome, which is influenced by several factors, such intrinsic (i.e. deficit in balance, gait, muscle strength, visual acuity, cognition and presence of disease and utilization of drugs) or extrinsic factors (i.e. home-related condition like lighting, prosthetic environment, loose rugs etc.) (Ishigaki et al., 2014; Rubenstein et al., 2001). Different types of interventions are recommended like systematic fall risk assessment, targeted interventions, exercise, and environmental supervision (Lee et al.,2013). Community-based interventions showed a decline of fall-related fractures in $6-33 \%$ of participants (McClure et al.,2005) and effectiveness of multi-factorial assessment and management (Gates et al,2008; Albert et al.,2014). Exercise and home safety interventions decreased the frequency and risk of falls, but intervention with only education and knowledge attainment were not successful (Gillespie et al,2012). Therefore, the aim of this study was to evaluate the effect of a 12-week balance, strength and aerobic training on balance and conditional tests in people 55 and over.

\section{Material and Methods}

After retrieving a permission from the local health department, a primary health care center in Serik district of Antalya province has been invited to participate. The health center was staffed with 2 primary care physicians and 4 nurses/midwifes. The staff underwent a two-hour training on falls prevention and falls. The content of the training included introduction to the project, scales and questionnaires, motivational interview, reason and prevention of falls, increasing physical activity, and practice of training. The training included the following workshops: measuring physical activity intensity, use of elastic bandages and Pilates balls, flexibility and endurance exercises. The physicians received exercise packs to distribute to their patients. The packs included following items: First Step Education Kit (RPE card, patient exercise 
manual, elastic bands [yellow, red, green, and blue], Pilates Balls, and questionnairescale files).

\section{Sample Size}

For a type I error rate of 0.05, type II error rate 0.2, proportion of IG 0f 0.5 , an effect size of 0.5 and a standard deviation of 1.0 a sample size of 126 (min 63 for IG and 63 CG) seems to be sufficient.

\section{Recruitment and Training of the Patients}

Patients aged 55 and over were invited by phone to participate in this study. The inclusion criteria was set as staying three months in their village, being able to walk 15 min vigorously, being 30 minutes walking distance away from the $\mathrm{PHC}$ center, and being free of any exercise hindering medical conditions. Individuals who were intensely manually and physically involved were not included in the study. Patients who fulfilled the inclusion criteria received a physical exam by physicians. Simple randomization of the patients was performed by HÇ from School of Physical Education at Anadolu University. The patients were blinded.

The patients of the intervention group were taught about the falls prevention program and instructed in endurance, strength, balance and flexibility training. The training included the use of elastic bands and plates balls, RPE scale, adjustment of walking intensity, increase of daily physical activity.

Patients were counseled by a consultant once a week. They received a manual for home exercises and elastic bands for strength training. Once a month, patients were supported with a new elastic band. Elastic bands had four different resistance levels (yellow, red, green and blue) and the patient received the weakest band first (mostly yellow) and changed the bands according to their progress. Further, they were instructed to exercise at home and at least 20 min endurance training. PHC center staff encouraged patients to exercise at home. The control group received 5-10 min information on falls and their consequences, benefits of physical activity, and ways to increase physical activity (Figure 1). 
Figure 1. Recruitment of patients and follow-up

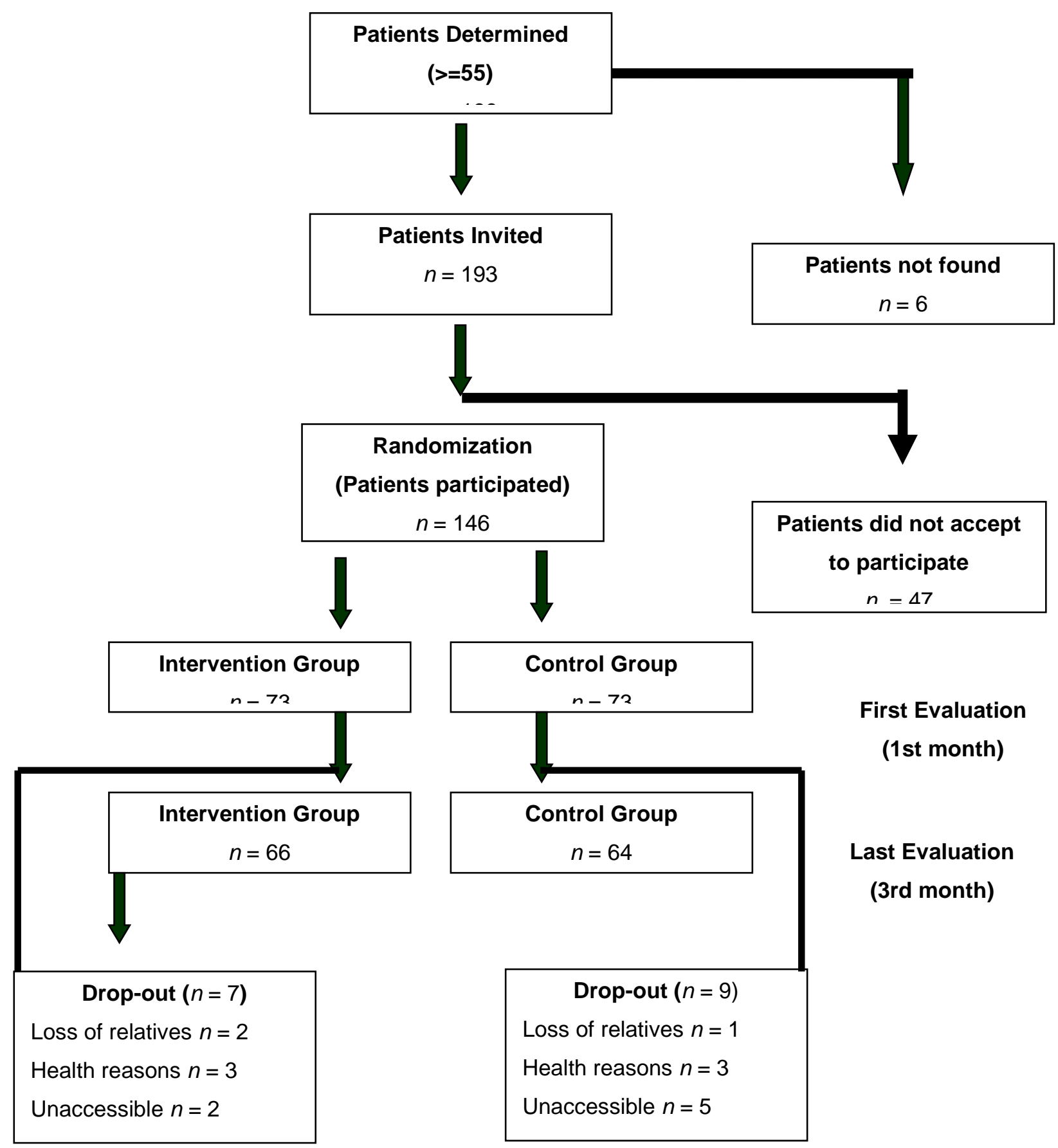




\section{Instruments}

Two measurements have been performed during this study. Physicians, nurses and surveyors were involved during the measurements and surveys. People involved were trained in measurements and surveys.

Instruments, which were not available in Turkish language (FAB, BES, HAQ) have been validated to Turkish. The procedure was as follows: first two translators translated the instruments into Turkish. Both translations were compiled by a third person two one document. Then this document was back-translated to English by two translators. Both back-translations were compiled to a final English version and this version was compared with the original instruments. After this procedure, the Turkish instruments were piloted in 10 persons, who were representative to the study sample and the final form of the instruments were drafted. Results of the pilot phase have been excluded from the study. Measurements and instruments used during this study are shown in Table 1.

Table 1. Instruments and measurements

\begin{tabular}{lcc}
\hline Instruments & $1^{\text {st }}$ Measurement & $2^{\text {nd }}$ Measurement \\
\hline Health and Activity Questionnaire & $\times$ & $\times$ \\
Balance Efficacy Scale & $\times$ & $\times$ \\
Fullerton Advanced Balance Scale (FAB) & $\times$ & $\times$ \\
Other Measurements: & $\times$ & $\times$ \\
Chair Stand Test (30 sec) & $\times$ & $\times$ \\
2-Minute Step in Place & $\times$ & $\times$ \\
Arm Curl Test & $\times$ & $\times$ \\
Chair Sit and Reach Test & $\times$ & $\times$ \\
Back Scratch Test & $\times$ & \\
50 Foot Walk Test (15 m) & & \\
\hline
\end{tabular}

Fullerton Advanced Balance Scale (FAB): The FAB includes the following 10 items designed to assess static and dynamic balance: standing eye closed, reaching an object, turning 360 degrees around, climbing up- and down stairs, standing on one feet, standing eyes closed on a foam ground, tandem walk, jumping with both feet, walking with rotated head, disbalance improving movements) (Rose et al.,2003). Responses were provided on a five-point ordinal scale (ranging from 0 to 4 ) with a maximum score of 40 points. 
Balance Efficacy Scale (BES): The BES includes18 items designed to measure self-perceived confidence of an individual's ability in successfully performing a given task without losing balance. The items were information on disbalance during standing-up from chair, climbing and walking down stairs, lying down and standingup, reaching to a high cupboard shelf with/without support, and during passing the road at day and night-time, dressing, and daily activities (Brill,2004).

Health/Activity Questionnaire (HAQ) of the Falls Prevention Program. This questionnaire assesses participants' disease, medication, accidents and fall frequency, and physical activity levels (Rose,2003).

\section{Measurements}

Sensory Fitness Tests: These tests (30 second chair stand test, arm crawl test, 2-minute step test, sit-and-reach test, and back scratch test) help to determine the strength, speed, flexibility and endurance of lower and upper extremities. To guarantee a better test performance the testing place has been isolated and tests performed in groups. The participants were dressed appropriately and each participant received an explanation on the tests performed. Each participant was included after a 3.5 min warming exercise. Every test unit was observed, controlled and supported by an examiner. The PHC Centers was alerted to intervene for a medical condition during the examinations (Brill,2004).

Chair Stand Test: The height of the chair was $43.18 \mathrm{~cm}$ (12 inch) and the participant sat straight in the middle of the chair, crossing his arms at thoracic level.The number of stand-ups during 30 min were recorded (Rikli and Jones,2001).

Arm Curl Test: The participant seated at the edge of the chair and used the dominant arm to lift a weight (Women $=2.27 \mathrm{~kg} \&$ Men $=3.63 \mathrm{~kg}$ ) down from extension up to flexion (Rikli \& Jones, 2001).

Two Minutes Step Test: The participant was expected to raise the knee up to the mid-point of a line between iliac crest and patella. The number of right knee raises within two minutes was counted. Only knee raises reaching the midpoint level was accepted (Rikli \&Jones, 2001).

Chair Sit and Reach Test: This is a modification of the sit and reach test. The participants sit on a $43.18 \mathrm{~cm}$ high chair, one leg stretch and heel touching the ground; other leg flexed 90 degrees and foot completely touching the ground. Both hands were added up to another and both middle fingers join together. Both hands 
were stretched forward along the stretched leg and trying to touch the tip of the foot. The distance of both middle fingers to the feet were measured and registered (in minus cms) (Rikli \& Jones,2001).

Back Scratch Test: The participant tries to touch both finger ends from behind. The distance between both middle finger tips were measured (minus $\mathrm{cm}$ distance) (Rikli and Jones, 2001).

Fifty feet walk test. The walking time during a 15-meter distance was measured (Albert et al., 2014).

\section{Practice of Exercise Prescriptions}

Exercise involving strength, endurance, balance and flexibility training were used in this program. Before prescribing, the patient was instructed to start low intensity exercise for two weeks. After prescription, the frequency was three times a week. Daily 1-3 sets and max. 10 repetitions per set were recommended. The frequency and duration of exercise have been increased progressively. The frequency was increased from 4 to 5 times a week. Moderate intensity endurance training was recommended (i.e. walking, swimming, cycling). The duration had been increased by 5 minutes and at the end of 3 months the duration of exercise was 30 minutes. Flexibility was included into the warm-up and cool-down phase. The moderate intensity strength prescription included elastic bands. Bands were exchanged every month by measurement of strength development.

Exercise intensity was estimated by using the talk test during walking and jogging and the Rate of Perceived Exhaustion (RPE). A level of 12-14 RPE was accepted as moderate intensity and recommended to the participants. Balance training was prescribed after strengthening exercise reached a certain level.

Balance training was recommended three times a week. Foam peds, elastic balls and chair were used for balance exercises. First Step Set was used as reference with pictures by patients. The exercises began with one set and increased to three sets. Jumping exercises were not allowed. The exercise prescription was prepared individual specific. The prescription was renewed once a month. Table 2 demonstrates the exercise prescription recommendations. 
Table 2. Exercise prescription recommendations

\begin{tabular}{lccc}
\hline & Frequency & Duration & Intensity \\
\hline Endurance & $3-5 /$ week & $10-40$ min. & RPE 12-14 \\
Strength & $2-3 /$ week & $1-3$ set & RPE 12-14 \\
Flexibility & 2-3/ week & 10 repetitions & \\
& & 5-10 Flexibility Exercise & \\
Balance & 1-4 set \\
& 2-3/week & 10-30 sec & \\
Warm-up \& Cool-down & Each Training Period & 8-10 Balance Exercise & \\
\end{tabular}

*Brill PA. Functional Fitness for Older Adults. United Kingdom. Human Kinetics. 2004

\section{Safety of Participants}

Participants passing the physical exams were eligible for participation. This study was of low risk, because participants could adjust their own exercise intensity. The PHC center staff was available for any emergency intervention during the measurements. Participants were accompanied to help and support during disbalance.

\section{Ethical Approval}

Participants gave consent to participate in this study.

\section{Statistical Analysis}

Two independent variables were available in this study: Group and Time. Dependent variables were measures and instruments (questionnaires) of balance. Student t-test, Mann Whitney $U$ test, Wilcoxon Signed Ranks Test, and t test for dependent variables have been applied. Level of significance was set to alpha=0.05.

\section{Results}

This study started with 73 intervention group (IG) and 73 control group (CG), 146 in total participants. At the end of the study (12th week) the IG had 66 and the control group 64 participants. All participants were sedentary at the beginning and no 
health condition, which hindered to exercise. Table 3 demonstrates the sociodemographic properties of the participants.

Table 3. Sociodemographic properties of participants

\begin{tabular}{lcc}
\hline & $\begin{array}{c}\text { Intervention Group (\%) } \\
(n=66)\end{array}$ & $\begin{array}{c}\text { Control Group (\%) } \\
(n=64)\end{array}$ \\
\hline Gender & 39.4 & 39.4 \\
Male & 66.6 & 66.6 \\
Female & & \\
Age & 37.9 & 37.3 \\
$55-60$ & 18.2 & 16.4 \\
$61-65$ & 21.2 & 29.9 \\
$66-70$ & 12.1 & 7.4 \\
$71-75$ & 10.6 & 9 \\
$76-80$ & & 95.5 \\
Social Security & 97 & 4.5 \\
Yes & 3 & 75.7 \\
No & & - \\
Marital Status & 68.1 & 24.2 \\
Married & 1.4 & \\
Single & 30.3 & \\
Widowed & & \\
\hline
\end{tabular}

Some items of the Falls Prevention Program Health/Activity Questionnaire revealed following results (see Table 4)

Table 4. Health and activity questionnaire results

\begin{tabular}{lcc}
\hline Frequency of falls (last one year) & IG (\%) & CG(\%) \\
0 & 73.5 & 53.1 \\
1 & 14.3 & 20.4 \\
2 & 6.1 & 10.2 \\
3 & 2 & 2 \\
4 & 2 & 2 \\
5 & 0 & 2 \\
6 & 2 & 2 \\
10 & - & 2 \\
15 & - & 2 \\
\hline & IG (\%)
\end{tabular}




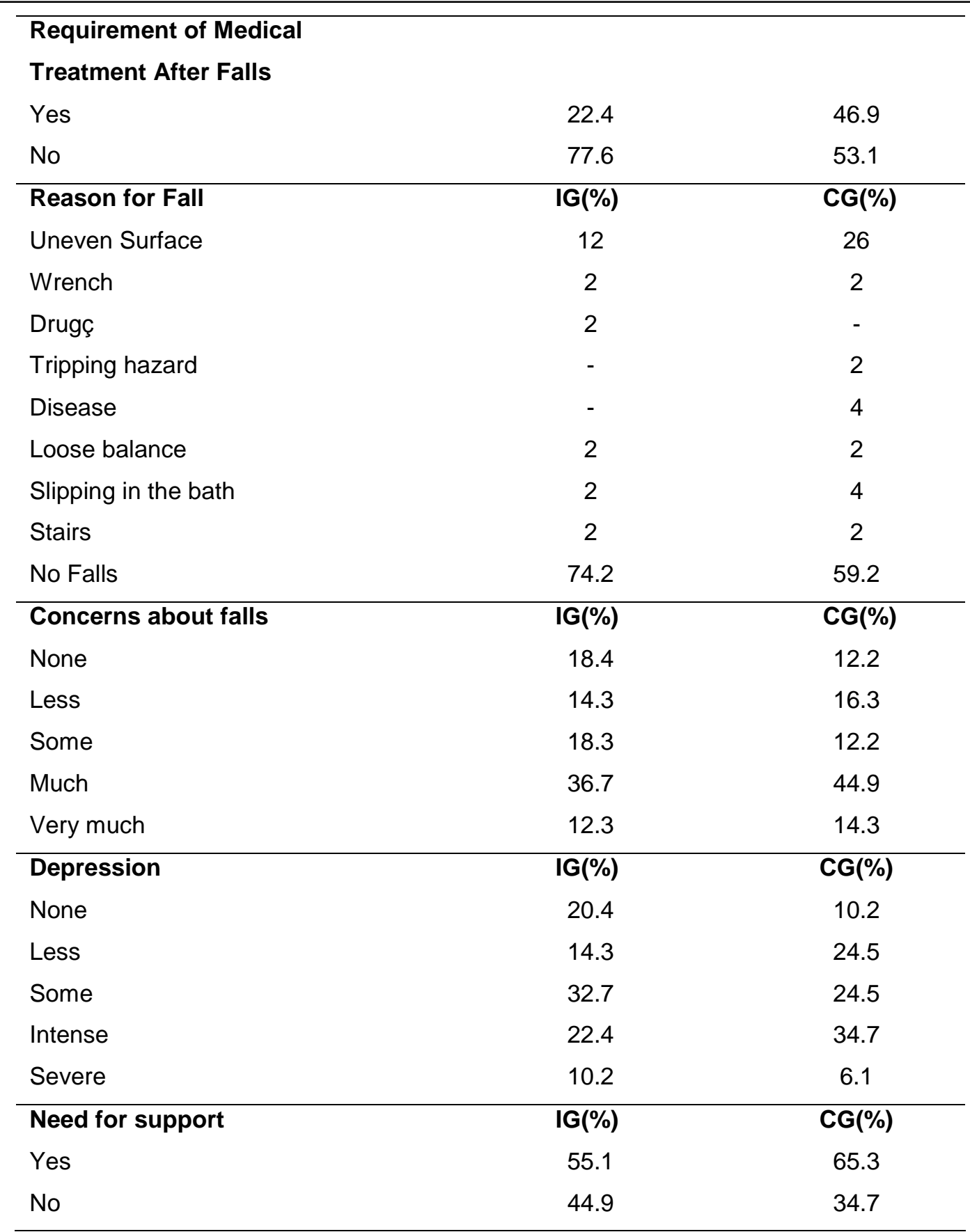

The comparison of the measurements of IG and CG at baseline and after intervention at week 12 are shown below. No significant relation between baseline values have been observed (see Table 5). 
Table 5. Baseline Values of Measurements and Instruments

\begin{tabular}{|c|c|c|c|c|c|}
\hline \multirow[t]{2}{*}{ Instruments and Measurements } & \multicolumn{2}{|c|}{$\begin{array}{l}\text { Intervention group } \\
\qquad(n=66)\end{array}$} & \multicolumn{2}{|c|}{$\begin{array}{l}\text { Control group } \\
\qquad(n=66)\end{array}$} & \multirow{2}{*}{$\begin{array}{l}\text { Between } \\
\text { Groups }(p)\end{array}$} \\
\hline & $M$ & $S D$ & $M$ & $S D$ & \\
\hline Age (Years) & 64.30 & 7.10 & 64.35 & 7.28 & $0.966^{\mathrm{a}}$ \\
\hline Balance Efficacy Scale (\%) (max 100\%) & 75.97 & 16.51 & 74.27 & 17.19 & $0.575^{a}$ \\
\hline FAB (Scores) (max 40) & 21.88 & 7.55 & 22.11 & 8.03 & $0.909^{a}$ \\
\hline Chair-Stand-Test (frequency) & 9.72 & 2.80 & 9.58 & 2.672 & $0.554^{\mathrm{a}}$ \\
\hline Two Minutes Step Test (frequency) & 36.19 & 11.47 & 36.59 & 10.56 & $0.919^{a}$ \\
\hline Arm Curl Test & 14.94 & 3.42 & 14.64 & 3.86 & $0.463^{\mathrm{a}}$ \\
\hline Chair Sit and Reach Test (cm) & -4.82 & 9.30 & -4.55 & 9.30 & $0.785^{\mathrm{a}}$ \\
\hline Back Scratch Test (cm) & -15.73 & 10.319 & -15.21 & 9.51 & $0.764 \mathrm{e}$ \\
\hline Fifty Feet Walk Test (sec) & 15.42 & 2.83 & 15.55 & 2.81 & 0.817 \\
\hline
\end{tabular}

aMann Whitney U test, eStudent t-test, * $p=0.05$

Changes between and within groups revealed following results (see Table 6)

Table 6. Changes in the differences between and within groups

\begin{tabular}{|c|c|c|c|c|c|}
\hline $\begin{array}{l}\text { Instruments and } \\
\text { Measures }\end{array}$ & $\begin{array}{l}\text { Intervention } \\
\text { Difference }\left(3^{\text {rd }}\right. \\
\text { month-basal) }\end{array}$ & $p$ & $\begin{array}{l}\text { Control } \\
\text { Difference ( } 3^{\text {rd }} \\
\text { month-basal) }\end{array}$ & $p$ & $\begin{array}{c}\text { Groups } \times \text { Time } \\
(p)\end{array}$ \\
\hline $\begin{array}{l}\text { Balance Efficacy Scale } \\
(\%)(\max 100 \%)\end{array}$ & $3.52 \pm 13.01$ & $p<0.001^{b}$ & $-.84 \pm 4.26$ & $\begin{array}{l}p= \\
0.111^{d}\end{array}$ & ${ }^{\star} \mathrm{p}<0.001^{\mathrm{a}}$ \\
\hline $\begin{array}{l}\text { Fullerton Advanced } \\
\text { Balance Scale } \\
\text { (Scores) }(\max 40)\end{array}$ & $4.31 \pm 3.86$ & $p<0.001^{d}$ & $1.00 \pm 3.11$ & $p=0.011^{d}$ & ${ }^{*} p<0.001^{a}$ \\
\hline $\begin{array}{l}\text { Chair-Stand-Test } \\
\text { (frequency) }\end{array}$ & $1.55 \pm 1.36$ & $p<0.001^{b}$ & $-1.106 \pm 1.40$ & $\mathrm{p}=0.393^{\mathrm{b}}$ & ${ }^{*} p<0.001^{a}$ \\
\hline $\begin{array}{l}\text { Two Minutes Step Test } \\
\text { (frequency) }\end{array}$ & $3.29 \pm 7.49$ & $p<0.001^{b}$ & $-1.46 \pm 3.77$ & $p<0.001^{b}$ & ${ }^{*} p<0.001^{a}$ \\
\hline Arm Curl Test & $1.77 \pm 4.42$ & $\mathrm{p}<0.001^{b}$ & $-0.69 \pm 2.60$ & $p=0.003^{b}$ & ${ }^{*} \mathrm{p}<0.001^{\mathrm{a}}$ \\
\hline $\begin{array}{l}\text { Chair Sit and Reach } \\
\text { Test (cm) }\end{array}$ & $1.61 \pm 2.92$ & $\mathrm{p}<0.001^{b}$ & $-0.28 \pm 4.08$ & $p=0.237^{b}$ & ${ }^{*} p<0.001^{a}$ \\
\hline $\begin{array}{l}\text { Back Scratch Test } \\
(\mathrm{cm})\end{array}$ & $1.52 \pm 3.05$ & $p<0.001^{d}$ & $0.09 \pm 3.126$ & $p=0.814^{d}$ & ${ }^{*} p<0.001^{a}$ \\
\hline $\begin{array}{l}\text { Fifty Feet Walk } \\
\text { Test (sec) }\end{array}$ & $-1.10 \pm 0.76$ & $\mathrm{p}<0.001^{b}$ & $-0.03 \pm 1.36$ & $p=0.788^{b}$ & ${ }^{*} p<0.001^{a}$ \\
\hline
\end{tabular}


Table 7. The Effect of exercise on the frequency of falls

\begin{tabular}{|c|c|c|}
\hline \multicolumn{3}{|c|}{ Frequency of Falls (last 1} \\
\hline \multicolumn{2}{|c|}{0} & 73.5 \\
\hline \multicolumn{2}{|c|}{1} & 14.3 \\
\hline \multicolumn{2}{|c|}{2} & 6.1 \\
\hline \multicolumn{2}{|c|}{3} & 2 \\
\hline \multicolumn{2}{|c|}{4} & 2 \\
\hline \multicolumn{2}{|c|}{5} & 0 \\
\hline \multicolumn{2}{|c|}{6} & 2 \\
\hline \multicolumn{2}{|c|}{10} & 0 \\
\hline \multicolumn{2}{|c|}{15} & 0 \\
\hline \multicolumn{2}{|l|}{ Groups } & $\mathbf{p}$ \\
\hline IG & CG & $0.340^{*}$ \\
\hline IG & IG $3^{\text {rd }}$ month & $1.00^{*}$ \\
\hline CG & $\mathrm{CG} 3^{\text {rd }}$ month & $1.00^{*}$ \\
\hline \multirow[t]{2}{*}{ IG $3^{\text {rd }}$ month } & CG $3^{\text {rd }}$ month & $0.340^{*}$ \\
\hline & CG & \\
\hline IG difference & difference & $0.785^{\star}$ \\
\hline
\end{tabular}

*Wilcoxen Signed Ranks Test

\section{Discussion}

The Balance Efficacy Scale score, The Fullerton Advanced Balance Scale score, Chair Stand Test repetition frequency, Sit and Reach Test, Back Scratch Test, Arm Curl Test, Two Minutes Step Test, and the Fifty Feet Walk Test showed a significant difference at the end of the intervention and in the intervention group.

Different factors of falls have been described. These might be also cultural dependent and differ from country to country. This might be also the case for Turkey. Halil et al. mention that the mainly preventive health concerning elderly people need to be well defined and control of factors related to falls and their prevention need to be evaluated. In their study the prevalence of falls at least once within a year has been found \%28.5 (Halil ve ark.,2006). Our study is an attempt to create a community-based exercise model to prevent falls in community.

Even our study did not reveal a decrease in falls, multi-component group and home-based exercise interventions significantly reduced the frequency and risk of 
falls. Generally, exercise interventions decreased the risk of a fracture after falls (Gillespie et al.,2012).

Our study significantly improved balance and functional performance after a 12-week intervention. These results are comparable with the multifactorial fall prevention program by Lee et al. (Lee et al.,2013) with a similar exercise intervention duration of 3 months in people living in community. This intervention did not reduce falls during a one-year follow-up.

Unsupervised home exercise was effective to improve balance, mobility and flexibility (Clemson et al.,2012). Optimal training modality has been found to be balance and lower extremity exercises (Gillespie,2012;Ishigaki,2014 et al.; Sherrington et al.,2008), but the compliance remains still low in elderly people (Clemson et al.,2012) and the delivery of the most effective intervention to the right group is a major challenge (Freiberger et al.,2013;Ganz et al.,2008) USPSTF recommends group classes and physiotherapy, which includes balance training $>=3$ days a week in elderly high-risk fallers, which is also supported by the American Geriatric Society (Moyer,2012). To avoid detraining effects the exercise needs to be sustainable (Lee et al,2013).

Strength training has been observed to improve additionally balance, flexibility and functionality (Ishigaki et al.,2014) and seems to be essential to prevent falls (Clemson et al.,2012). The sit-to-stand exercise has been widely applied, because it involves a frequent daily activity. This exercise was related to the decrease of falls (Ishigaki et al.,2014;Clemson et al.,2012). Our study showed also an improvement in lower extremity performance test after intervention.

Besides the intensity, frequency, and load of exercises; the length might play a role in the prevention falls. Sherrington et al. reported that a training at least of 25 weeks might be ideal (Sherrington et al,2008) and Ishigaki et al. mentions at least 6 months and a frequency of at least three times per week as ideal (Ishigaki et al,2014). Our 12-week intervention might have been too short to show a benefit on the frequency of falls, even significant conditional results could be retrieved. Gains of exercise are lost within 12 weeks (Vogler et al.,2012).

\section{Conclusion}

Our study revealed positive changes in conditional factors involving strength, flexibility and balance. But a decrease in fall frequency could not be observed. The 
reason might be the reliance on self-report, where elderly were asked to report the frequency of their own falls or the modest or non-reduction of fall risk and incidence after interventions and multifactorial assessments. Lee $\mathrm{HC}$ et al. reported improved functionality at 12 weeks of exercise intervention without a falls decrease after one year follow-up (Lee et al.,2013). Home-based exercise interventions have been found to reduce the rate and multifactorial assessments the risk of falling (Gillespie et al.,2001). Our study recommends a promising primary care-based intervention, which might reduce falls after a sustainable and long-term intervention. The primary care physician and an assisting consultant should be at the center of such kind of intervention to guarantee successful outcomes.

\section{Acknowledgement}

The data of this study has been partially retrieved from a Master of Science Dissertation by Şirin Topçu (The Effect Of A 12 Week Balanace, Strength And Aerobic Exercise Program On Falls In Elderly Over 55). Akdeniz University Institute of Health Sciences master of Science Thesis. 2009). This study has been supported by Thera-Band, GmbH, Hadamar, Germany. 


\section{References}

Albert SM, King J, Boudreau R, Prasad T, Lin CJ Newman AB.(2014). Primary

Prevention of Falls: Effectiveness of a Statewide Program. Am J Public Health. 104:e77-e84. doi:10.2105/AJPH.2013. 301829

Brill PA.(2004) Functional Fitness for Older Adults. United Kingdom. Champaign, IL: Human Kinetics.

Clemson L, Singh MAF, Bundy A, Cumming RG, Manollaras K, O'Loughlin P, Black D. (2012). Integration of balance and strength training into daily life activity to reduce rate of falls in older people (the LiFE study): randomised parallel trial.BMJ.

Freiberger E, Blank WA, Salb J, et al.(2013). Effects of a complex intervention on fall risk in the general practitioner setting: a cluster randomized controlled trial. Clin Interv Aging.8:1079-1088.Published online 19. doi: 10.2147/CIA.S46218

Ganz DA, Alkema GE, Wu S. (2008).It takes a village to prevent falls:

reconceptualizing fall prevention and management for older adults. Inj Prev. 14(4):266-271.

Gates S, Lamb SE, Fisher JD, Cooke MW, Carter YH. (2008). Multifactorial assessment and targeted intervention for preventing falls and injuries among older people in community and emergency care settings: systematic review and meta- analysis. BMJ. 336(7636):130---133

Gillespie L, Robertson M, Gillespie W, et al. (2012). Interventions for preventing fall in older people living in the community. Cochrane Database Syst Rev. 9:CD007146.

Halil M1, Ulger Z, Cankurtaran M, Shorbagi A, Yavuz BB, Dede D, Ozkayar N, Ariogul S.(2012) Falls and the elderly: is there any difference in the developing world? A cross-sectional study from Turkey. Arch Gerontol Geriatr. 2006 NovDec;43(3):351-9. Epub 2006 Mar 7.345: e4547. Published online 2012 August 7. doi: 10.1136/bmj.e4547

Ishigaki EY, Ramos LG, Carvalho ES, Lunardi AS. (2014). Effectiveness of muscle strengthening and description of protocols for preventing falls in the elderly: a systematic review. Braz J Phys Ther. Mar-Apr; 18(2):111-118.

Lee HC, Chang KC, Tsauo JY, et al. (2013).Effects of a Multifactorial Fall Prevention Program on Fall Incidence and Physical Function in Community-Dwelling Older Adults With Risk of Falls. Archives of Physical Medicine and 
Rehabilitation 94:606-15

McClure R, Turner C, Peel N, et al. (2005).Population-based interventions for the prevention of fall-related injuries in older people. Cochrane Database Syst Rev. 2:CD004441

Moyer VA. (2012). Preventive Services Task Force. Prevention of falls in communitydwelling older adults: U.S. Preventive Services Task Force recommendation statement. Ann Intern Med. Aug 7;157(3):197-204.

Panel on Prevention of Falls in Older Persons, American Geriatrics Society and British Geriatrics Society. (2011). Summary of the Updated American Geriatrics Society/British Geriatrics Society clinical practice guideline for prevention of falls in older persons. J Am Geriatr Soc. 59:148-57.

Rikli RE, Jones JC. (2001). Senior fitness test manual Champaign, IL: Human Kinetics.

Rose DJ. (2003) Fall Proof: A Comprehensive Balance and Mobility Training Program. Champaign, IL: Human Kinetics.

Rubenstein LZ, Powers CM, MaClean CH.(2001). Quality indicators for the management and prevention of falls and mobility problems in vulnerable elders. Ann Intern Med. 135(8):686-93. PMid: 11601951. doi:10.7326/00034819-135- 8_Part_2-200110161-00007

Sherrington C, Whitney JC, Lord SR, Herbert RD, Cumming RG, Close JCT. (2008)Effective exercise for the prevention of falls: a systematic review and meta-analysis. J Am Geriatric Soc 56:2234-43.

Tinetti ME, Speechley M, Ginter SF. (1988).Risk factors for falls among elderly persons living in the community. N Engl J Med. 319:1701-7.

Vogler CM, Menant JC, Sherrington C, Ogle SJ, Lord SR. (2012). Evidence of detraining after 12-week home-based exercise programs designed to reduce fall-risk factors in older people recently discharged from hospital. Arch Phys Med Rehabil 93:16 